\section{New light in flavin autofluorescence}

\section{A.C. Croce, G. Bottiroli}

Histochemistry and Cytometry Unit, IGMCNR, Biotechnology and Biology Department, University of Pavia, Italy

\section{Abstract}

Our attention was captured by the interesting debate on the identification of lipofuscins, lipofuscin-like lipopigments, or flavins as the responsible for intracellular autofluorescence (AF) detected in epithelial cancer stem cells when exciting at $480-490 \mathrm{~nm}$. Evidence was provided leading to ascribe $\mathrm{AF}$ emission to flavins accumulating in cytoplasmic structures, bounded to membranes and bearing ATP-dependent ABCG2 transporters. Flavins were then proposed as an intrinsic AF biomarker of cancer stem cells, with advantageous implications on cell invasiveness and chemoresistance investigations. It is however worth recalling the huge amount of literature on flavins and $\mathrm{NAD}(\mathrm{P}) \mathrm{H}$ as $\mathrm{AF}$ biomarkers of cell energetic metabolism and redox state, an aspect that should not be overlooked in the renewed course to extend the potential of flavins as AF biomarkers, entailing also a recent proposal of Flavin-based fluorescent proteins as substitutes of Green fluorescent proteins.

\section{Introduction}

The interesting debate on the possible contribution of lipofuscins or flavins to intracellular autofluorescence (AF) in epithelial cancer stem cells ${ }^{1-3}$ captured our attention. The discussion making also reference to our recent review on $\mathrm{AF}$ in the biomedical field, ${ }^{4}$ ended with the identification of flavins as the real primary responsible for AF signal. The almost exclusive presence of flavins was substantiated by the sole AF response to their proper excitation/emission conditions. A contribution from lipofuscins or lipofuscin-like lipopigments was excluded, since the use of wider spectral ranges in AF excitation/emission matching their broader and variable spectral properties did not result in an appreciable AF response detection. ${ }^{2}$ In addition, reversible changes were reported for the AF signal when cells were treated with agents inhibiting ATP production. These AF changes, likely inconsistent with reversible loss of lipofuscin-like lipopigments upon administration of mito- chondrial poisons, were ascribed to fluctuations of flavin AF emission. Riboflavin was therefore proposed to accumulate in cytoplasmic structures bounded to membranes and bearing ATP-dependent ABCG2 transporters, acting as an intrinsic AF biomarker of cancer stem cells with promising implications for invasiveness and chemoresistance investigation. In this concern, however, it is to remind that participation of flavins and $\mathrm{NAD}(\mathrm{P}) \mathrm{H}$ as coenzymes in redox reactions makes them to act as AF biomarker of cell redox state and engagement in energy metabolism, as from the huge amount of data reported up to now in literature. ${ }^{5-13}$

\section{Autofluorescence of flavins and cell functions}

In general, the AF emission from single cells and its variations depend both on the actual presence of $\mathrm{NAD}(\mathrm{P}) \mathrm{H}$ and flavins and on their redox state, considering that these endogenous fluorophores are usually the main responsible for the overall signal from single cells, and that they fluoresce in their respective reduced and oxidized state. ${ }^{8,9,14,15}$ The redox state of the two coenzymes, in turn depends on their strict involvement in reaction pathways of energy metabolism, reductive biosynthesis and antioxidant defense..$^{6,7,15-17}$ As reminded in our recent review on $\mathrm{AF}$ in cells and tissues,${ }^{4}$ the participation of flavins and $\mathrm{NAD}(\mathrm{P}) \mathrm{H}$ as coenzymes in intracellular reactions leading to ATP production, and the dependence of their AF emission signals on redox state inspired the pionieristic studies of Duysen, Britton Chance and coworkers on energy metabolism. ${ }^{8,10,14,15,17-19}$ The ensuing massive works enforced step by step the importance of $\mathrm{NAD}(\mathrm{P}) \mathrm{H}$ and flavins as AF biomarkers of energy and redox state of cells and tissues. ${ }^{8,20-25}$ The combined AF analysis of these two endogenous fluorophores was thus at the basis of remarkable experimental investigations and applications in biomedicine for the in situ assessment and real time monitoring of organ or cell functionality, ${ }^{26-30}$ providing direct information on cell and tissue response ability to external stimuli or on cell intrinsic features, such as stemness degree and cancer transformation. ${ }^{6,22,31-35}$

Therefore, it is advisable that the role of flavins and $\mathrm{NAD}(\mathrm{P}) \mathrm{H}$ as $\mathrm{AF}$ biomarkers of cell energy and redox status will be not disregarded, in particular when excitation/emission conditions proper for these endogenous fluorophores are used and the effects of substances affecting mitochondrial activity are investigated. Obviously this recommendation applies in particular to in vivo cell investiga-
Correspondence: Dr. Anna Cleta Croce, IGM-CNR, Sezione Istochimica e Citometria, Dipartimento di Biologia Animale, Università degli Studi di Pavia, Palazzo Botta 2, via A. Ferrata 9, 27100 Pavia, Italy.

Tel. +39.0382.986428; Fax: +39.0382.986430.

E-mail: croce@igm.cnr.it

Key words: Endogenous-fluorophores; NAD(P)H; energetic metabolism; redox state.

Conflict of interest: the authors report no conflicts of interest.

Funding: the Authors wish to thank Fondazione Cariplo, grant n. "2011-0439", for supporting their work.

Received for publication: 15 October 2015

Accepted for publication: 28 0ctober 2015

This work is licensed under a Creative Commons Attribution NonCommercial 3.0 License (CC BYNC 3.0).

(C) Copyright A.C. Croce and G. Bottiroli, 2015

Licensee PAGEPress, Italy

European Journal of Histochemistry 2015; 59:2576 doi:10.4081/ejh.2015.2576

tions performed in the absence of exogenous markers, since the relatively faint native $\mathrm{AF}$ from mitochondria could be likely hidden by the stronger emission from fluorescent dyes used for specific organelle labelling, and consequent instrumental adjustments.

In conclusion, besides the potential of flavin and $\mathrm{NAD}(\mathrm{P}) \mathrm{H}$ AF analysis to provide information on cell energy metabolism engagement and redox state, and on their changes possibly related with adherence, tumor generation and chemoresistance, the novelty on flavins as $\mathrm{AF}$ biomarkers of transporters, ${ }^{1}$ as well as on Flavin-based fluorescent proteins ${ }^{36}$ can be expected to improve AF application leading to a more comprehensive investigation of cell functions and biological properties.

\section{References}

1. Miranda-Lorenzo I, Dorado J, Lonardo E, Alcala S, Serrano AG, Clausell-Tormos J, et al. Intracellular autofluorescence: a biomarker for epithelial cancer stem cells. Nat Methods 2014;11:1161-9.

2. Sainz B, Miranda-Lorenzo I, Heeschen C. The fuss over lipo'fuss'cin: not all autofluorescence is the same. Eur J Histochem 2015;59:2512.

3. Di Guardo G. Lipofuscin, lipofuscin-like pigments and autofluorescence. Eur $\mathrm{J}$ Histochem 2015;59:2485. 
4. Croce AC, Bottiroli G. Autofluorescence spectroscopy and imaging: a tool for biomedical research and diagnosis. Eur $\mathrm{J}$ Histochem 2014;58:2461.

5. Kunz WS. Evaluation of electron-transfer flavoprotein and alpha-lipoamide dehydrogenase redox states by two-channel fluorimetry and its application to the investigation of beta-oxidation. Biochim Biophys Acta 1988;932:8-16.

6. Heikal AA. Intracellular coenzymes as natural biomarkers for metabolic activities and mitochondrial anomalies. Biomark Med 2010;4:241-63.

7. Georgakoudi I, Quinn KP. Optical imaging using endogenous contrast to assess metabolic state. Annu Rev Biomed Eng 2012;14:351-67.

8. Chance B, Schoener B, Oshino R, Itshak F, Nakase Y. Oxidation-reduction ratio studies of mitochondria in freeze-trapped samples. NADH and flavoprotein fluorescence signals. J Biol Chem 1979;254:4764-71.

9. Kunz WS. Spectral properties of fluorescent flavoproteins of isolated rat liver mitochondria. FEBS Lett 1986;195:92-6.

10. Chance B, Cohen P, Jobsis F, Schoener B. Intracellular oxidation-reduction states in vivo. Science 1962;137:499-508.

11. Mayevsky A, Barbiro-Michaely E. Shedding light on mitochondrial function by real time monitoring of NADH fluorescence: II: human studies. J Clin Monit Comput 2013;27: 125-45.

12. Shuttleworth CW. Use of $\mathrm{NAD}(\mathrm{P}) \mathrm{H}$ and flavoprotein autofluorescence transients to probe neuron and astrocyte responses to synaptic activation. Neurochem Int 2010;56:379-86.

13. Salmon JM, Kohen E, Viallet P, Hirschberg JG, Wouters AW, Kohen C, et al. Microspectrofluorometric approach to the study of free/bound $\mathrm{NAD}(\mathrm{P}) \mathrm{H}$ ratio as metabolic indicator in various cell types. Photochem Photobiol 1982;36:585-93.

14. Duysens LN, Amesz J. Fluorescence spectrophotometry of reduced phosphopyridine nucleotide in intact cells in the near-ultraviolet and visible region. Biochim Biophys Acta 1957;24:19-26.

15. Thorell B. Flow-cytometric monitoring of intracellular flavins simultaneously with NAD(P)H levels. Cytometry 1983;4:61-5.
16. Nakamura M, Bhatnagar A, Sadoshima J. Overview of pyridine nucleotides review series. Circ Res 2012;111:604-10.

17. Chance B, Thorell B. Fluorescence measurements of mitochondrial pyridine nucleotide in aerobiosis and anaerobiosis. Nature 1959;184:931-4.

18. Scholz R, Thurman RG, Williamson JR, Chance B, Bücher T. Flavin and pyridine nucleotide oxidation-reduction changes in perfused rat liver. I. Anoxia and subcellular localization of fluorescent flavoproteins. J Biol Chem 1969;244:2317-24.

19. Chance B, Thorell B. Localization and kinetics of reduced pyridine nucleotide in living cells by microfluorometry. J Biol Chem 1959;234:3044-50.

20. Drozdowicz-Tomsia K, Anwer AG, Cahill MA, Madlum KN, Maki AM, Baker MS et al. Multiphoton fluorescence lifetime imaging microscopy reveals free-to-bound NADH ratio changes associated with metabolic inhibition. J Biomed Opt 2014;19: 086016.

21. Cannon TM, Shah AT, Walsh AJ, Skala MC. High-throughput measurements of the optical redox ratio using a commercial microplate reader. J Biomed Opt 2015;20: 010503.

22. Xu HN, Tchou J, Chance B, Li LZ. Imaging the redox states of human breast cancer core biopsies. Adv Exp Med Biol 2013;765: 343-9.

23. Sato B, Tanaka A, Mori S, Yanabu N, Kitai T, Tokuka A, et al. Quantitative analysis of redox gradient within the rat liver acini by fluorescence images: effects of glucagon perfusion. Biochim Biophys Acta 1995; 1268:20-6.

24. Shiino A, Matsuda M, Chance B. Threedimensional redox imaging of frozenquenched brain and other organs. Methods Enzymol 2002;352:475-82.

25. Huang S, Heikal AA, Webb WW. Two-photon fluorescence spectroscopy and microscopy of $\mathrm{NAD}(\mathrm{P}) \mathrm{H}$ and flavoprotein. Biophys J 2002;82:2811-25

26. Barbiro E, Zurovsky Y, Mayevsky A. Real time monitoring of rat liver energy state during ischemia. Microvasc Res 1998;56:253-60.

27. Mayevsky A, Walden R, Pewzner E, Deutsch A, Heldenberg E, Lavee J, et al.
Mitochondrial function and tissue vitality: bench-to-bedside real-time optical monitoring system. J Biomed Opt 2011;16: 067004.

28. Thorling CA, Crawford D, Burczynski FJ, Liu X, Liau I, Roberts MS. Multiphoton microscopy in defining liver function. $\mathrm{J}$ Biomed Opt 2014;19:90901.

29. Klauke H, Minor T, Vollmar B, Isselhard W, Menger MD. Microscopic analysis of $\mathrm{NADH}$ fluorescence during aerobic and anaerobic liver preservation conditions: a noninvasive technique for assessment of hepatic metabolism. Cryobiology 1998;36: 108-14.

30. Croce AC, Ferrigno A, Vairetti M, Bertone R, Freitas I, Bottiroli G. Autofluorescence spectroscopy of rat liver during experimental transplantation procedure. An approach for hepatic metabolism assessment. Photochem Photobiol Sci 2005;4: 583.

31. Santin G, Paulis M, Vezzoni P, Pacchiana G, Bottiroli G, Croce AC. Autofluorescence properties of murine embryonic stem cells during spontaneous differentiation phases. Lasers Surg Med 2013;45:597-607.

32. Rice WL, Kaplan DL, Georgakoudi I. Twophoton microscopy for non-invasive, quantitative monitoring of stem cell differentiation. PLoS One 2010;5:e10075.

33. Croce AC, Spano A, Locatelli D, Barni S, Sciola L, Bottiroli G. Dependence of fibroblast autofluorescence properties on normal and transformed conditions. Role of the metabolic activity. Photochem Photobiol 1999;69:364-74.

34. Croce AC, Fiorani S, Locatelli D, Nano R, Ceroni M, Tancioni F, et al. Diagnostic potential of autofluorescence for an assisted intraoperative delineation of glioblastoma resection margins. Photochem Photobiol 2003;77:309-18.

35. Wright BK, Andrews LM, Markham J, Jones MR, Stringari C, Digman MA, et al. NADH distribution in live progenitor stem cells by phasor-fluorescence lifetime image microscopy. Biophys J 2012;103:L7-9.

36. Mukherjee A, Walker J, Weyant KB, Schroeder CM. Characterization of flavinbased fluorescent proteins: an emerging class of fluorescent reporters. PLoS One 2013;8 e64753. 